\title{
RELATOS DE PESQUISAS \\ CONTEÚDOS EMERGENTES DA GESTÃO DA INFORMAÇÃO E DO CONHECIMENTO NOS CURSOS DE PÓS-GRADUAÇÃO EM CIÊNCIA DA INFORMAÇÃO NO BRASIL
}

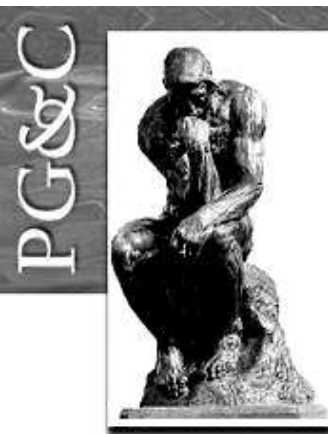

\author{
Emeide Nóbrega Duarte \\ Doutora em Administração pela Universidade Federal da Paraíba, Brasil. \\ Professora da Universidade Federal da Paraíba, Brasil. \\ E-mail: emeide@hotmail.com \\ Rayan Aramís de Brito Feitoza \\ Doutorando em Ciência da Informação pela Universidade Federal da \\ Paraíba, Brasil. Professor da Universidade Federal da Paraíba, Brasil. \\ E-mail: rayanbritof@gmail.com \\ Milena Ferreira Monteiro \\ Graduada em Biblioteconomia pela Universidade Federal da Paraíba, \\ Brasil. \\ E-mail: ferreiramonteiro29@gmail.com \\ Ana Raquel Pereira de Lima \\ Graduanda em Biblioteconomia pela Universidade Federal da Paraíba, \\ Brasil. \\ E-mail: anaraquelpl96@gmail.com
}

\section{Resumo}

Aborda a Gestão da Informação e a Gestão do Conhecimento nos cursos de pós-graduação em Ciência da Informação no Brasil. Objetiva analisar os conteúdos das disciplinas sobre Gestão da Informação e da Gestão do Conhecimento ofertadas nos cursos de pós-graduação em Ciência da Informação no Brasil. Metodologicamente, a pesquisa caracteriza-se como exploratória e descritiva, com abordagens quantitativa e qualitativa, do tipo documental realizado no ambiente da web. Adota como universo as instituições de ensino superior que oferecem cursos de pós-graduação em Ciência da Informação. Dessa maneira, considera a necessidade de trabalhar com a totalidade das universidades que oferecem o mencionado curso, para atingir uma análise mais ampla e resultados mais satisfatórios. Para organização e análise dos dados adota o método de análise de conteúdo. Os resultados obtidos relatam que os programas, na maioria, denominam-se de Ciência da Informação, suas linhas de pesquisa incorporam a Gestão da Informação e a Gestão do Conhecimento em seus estudos que vêm sendo ofertados nos níveis de mestrado (acadêmicos e profissionais) e doutorado. Os eixos-temáticos pertinentes à disciplina de Gestão da Informação e do Conhecimento são predominantes em cursos com alta avaliação pela Coordenação de Aperfeiçoamento de Pessoal de Nível Superior e tem grande predominância dos conteúdos das disciplinas em estudo. Apresenta perspectivas positivas em relação às abordagens que estão sendo inseridas nos cursos de pós-graduação em Ciência da Informação no Brasil e propõe conteúdos emergentes aos cursos dos Programas que ainda não ofertam o eixo-temático analisado.

Palavras-chave: Gestão da Informação e do Conhecimento. Gestão da Informação. Gestão do Conhecimento. Conteúdo Programático. Ciência da Informação. 


\title{
EMERGINGS CONTENTS OF INFORMATION AND KNOWLEDGE MANAGEMENT IN INFORMATION SCIENCE POS-GRADUATE COURSES IN BRAZIL
}

\begin{abstract}
Addresses Information Management and Knowledge Management in postgraduate courses in Information Science in Brazil. It aims to analyze the contents of the disciplines on Information Management and Knowledge Management offered in postgraduate courses in Information Science in Brazil. Methodologically, the research is characterized as exploratory and descriptive, with quantitative and qualitative approaches, the documentary type performed in the web environment. Adopts as a universe the higher education institutions that offer postgraduate courses in Information Science. Thus, it considers the need to work with all the universities that offer the mentioned course, to achieve a broader analysis and more satisfactory results. For data organization and analysis it adopts the content analysis method. The results show that most of the programs are called Information Science, their lines of research incorporate Information Management and Knowledge Management in their studies that have been offered at the Masters (academic and professional) levels doctorate degree. The thematic axes pertinent to the discipline of Information and Knowledge Management are predominant in courses with high evaluation by the Coordination of Improvement of Higher Education Personnel and have a great predominance of the contents of the subjects under study. It presents positive perspectives in relation to the approaches that are being inserted in the postgraduate courses in Information Science in Brazil and proposes emerging content to the programs courses that do not yet offer the thematic axis analyzed.
\end{abstract}

Keywords: Information and Knowledge Management. Information Management. Knowledge Management. Program Content. Information Science.

\section{INTRODUÇÃO}

Na metade do século $X X$, após segunda guerra mundial, surgem as necessidades de estudos quanto à identificação e organização de informações científicas e tecnológicas, com o objetivo de resolução para os problemas relativos à explosão informacional.

Nesse cenário, surge a Ciência da Informação $(\mathrm{Cl})$, apresentando característica interdisciplinar, considerando que diversas áreas tiveram papel fundamental na sua evolução devido à complexidade da informação, como seu objeto de estudo. Consequentemente, conforme apontam Bicalho e Oliveira (2011), há utilização de teorias e metodologias oriundas de outras áreas, assim como, uma diversidade de origem de formação e atuação de seu corpo científico.

Entendemos por interdisciplinaridade, como sendo qualquer forma de combinação entre duas ou mais disciplinas, buscando a compreensão de um objeto a partir da confluência entre pontos de vistas distintos resultando na elaboração de uma síntese comum ao objeto. Neste caso, os objetos determinados correspondem à informação e ao conhecimento, vistos de forma integrada, envolvendo a Biblioteconomia, a Ciência da Informação e a Administração (MOREIRA; VALENTIM; SANT'ANA, 2018).

Levando em consideração as características interdisciplinares da $\mathrm{Cl}$ e os diversos estudos ao longo das últimas décadas, esta área abarca em seu corpo teórico-metodológico a as subáreas que correspondem às tendências teóricas apontadas por Araújo (2014), como: os fluxos da informação científica, a representação e a recuperação da informação, os estudos de usuários, a gestão da informação e do conhecimento, a economia política da informação e os estudos métricos da informação.

Esta pesquisa aborda a subárea Gestão da Informação e do Conhecimento (GIC) como tema norteador, levando em consideração sua evolução no campo da $\mathrm{Cl}$ no Brasil. Estudos sobre os fluxos formais (gestão da informação) e informais (gestão do conhecimento) no

Perspectivas em Gestão \& Conhecimento, João Pessoa, v. 10, número especial, p. 176-200, mar. 2020. 
âmbito organizacional têm sido explorados significativamente por profissionais, pesquisadores e estudantes da pós-graduação nesta área.

É importante considerar que a GIC emerge ou surge em consonância com a Sociedade da Informação e do Conhecimento, onde esta representa uma profunda mudança em sua organização, havendo quem a considere um novo paradigma. Nessa Sociedade, as dinâmicas são afetadas pelo intenso fluxo de informações que atingem diversos setores, dentre eles, os educacionais, ocasionando mudanças no papel do docente que se transforma em mediador da aprendizagem, na tentativa de despertar no aluno, a capacidade de conhecer para inovar.

Para sobrevivência das organizações e qualquer atividade humana, a informação e o conhecimento são tão necessários que são vistos cada vez mais como uma força importante e poderosa que dão origem a expressões como: "Indústria da Informação", "Revolução da Informação", "Era da Informação", "Sociedade da Informação", "Sociedade do Conhecimento" e/ou "Sociedade da Informação e do Conhecimento".

Para Takahashi (2000, p. 7) "A dinâmica da sociedade da informação requer educação continuada ao longo da vida, que permita ao indivíduo não apenas acompanhar as mudanças tecnológicas, mas, sobretudo inovar." Para Bell (1976), a sociedade Pós-industrial é considerada uma "Sociedade do Conhecimento" porque as fontes de inovação são geradas no campo das pesquisas e, o peso dos bens constituídos na sociedade é cada vez mais proveniente no campo do conhecimento.

Toffler (1990) visualiza essas transformações na humanidade pela metáfora das ondas: a primeira corresponde à Sociedade Agrícola, onde a terra representava o principal recurso econômico caracterizada pela força muscular; a segunda corresponde à Sociedade Industrial, caracterizada pelo poder das máquinas, onde as empresas desfilavam como parques industriais compostos de máquinas e outros equipamentos. A terceira onda corresponde à Sociedade da Informação e do Conhecimento, onde a informação e o conhecimento assumem o papel de principais recursos econômicos, passando a ser caracterizada pelo poder do cérebro.

Vive-se, neste instante, um momento importante de transição do ambiente econômico, quando a gestão pró-ativa do conhecimento adquire um papel central para a competitividade tanto das empresas como dos países, devido à importância do conhecimento como recurso econômico e ao impacto da indústria de informação e telecomunicação (TERRA, 2000).

Considerando a Sociedade da Informação e do Conhecimento, Terra (2000) aponta os princípios que norteiam as organizações baseadas no conhecimento, são eles: valorização das pessoas como geradoras de receitas e ideias, promovendo interação entre os clientes, por intermédio de redes de comunicação e a valorização do conhecimento como foco do negócio, destacando a informação como poder e ferramenta para a comunicação.

Trazendo essas reflexões para o ensino e pesquisa sobre Gestão da Informação (GI) e Gestão do Conhecimento $(\mathrm{GC})$ na pós-graduação em $\mathrm{Cl}$ em nível brasileiro, foi preciso realizar um estudo nestes Programas, no intuito de compreender como vêm sendo abordados a GI e a GC ou Gestão da Informação e do Conhecimento (GIC) com relação aos aspectos estruturais e aos componentes curriculares dos cursos de mestrado (acadêmicos e profissionais) e no doutorado, levando em consideração as mudanças e adequações advindas pela Sociedade da Informação e do Conhecimento.

Para tanto, a problemática norteadora desta pesquisa foi definida pela seguinte questão: Que conteúdos são abordados nas disciplinas GI e GC nos cursos de pós-graduação em Ciência da Informação? Teve como objetivo geral analisar os conteúdos das disciplinas sobre Gl e GC ofertadas nos cursos de pós-graduação em Ciência da Informação no Brasil. Caso necessário, propor a inserção de conteúdos nas abordagens de Gl e GC em consonância com a

Perspectivas em Gestão \& Conhecimento, João Pessoa, v. 10, número especial, p. 176-200, mar. 2020. 
Sociedade da Informação e do Conhecimento refletidas nos programas pertinentes aos cursos de maior pontuação/notas obtidas na avaliação em nível nacional.

Este relato apresenta resultados de pesquisa do projeto de Iniciação Científica (IC) da Universidade Federal da Paraíba (UFPB), № PVE-2018 - edital - 01/2018 da Pró - Reitoria de Pesquisa (PROPESQ), intitulado "Abordagens da Gestão da Informação e do Conhecimento nos cursos de pós-graduação em Ciência da Informação no Brasil".

A seguir, apresentamos os fundamentos teóricos sobre a GIC no contexto da Ciência da Informação, os procedimentos metodológicos, os resultados e discussões e as considerações finais que compõem o corpus deste relato de pesquisa.

\section{A GESTÃO DA INFORMAÇÃO E DO CONHECIMENTO NO CONTEXTO DA CIÊNCIA DA INFORMAÇÃO}

Com o advento das tecnologias de informação e comunicação, grandes mudanças ocorreram nos contextos sociais, culturais e na dinâmica da economia global. Os avanços tecnológicos e a crescente utilização da internet contribuíram para uma reestruturação dos tradicionais processos de comunicação, disseminação da informação e obtenção do conhecimento. Essas transformações influenciaram diretamente a utilização da informação para a construção do conhecimento individual, seu armazenamento e compartilhamento.

Nesse sentido, as formas de lidar com a informação e com o conhecimento em ambientes organizacionais começaram a ser pensadas, pesquisadas e inovadas por meio de condutas de gestão que possibilitassem a eficiência e a eficácia no processo de competitividade e melhoria na qualidade de seus serviços.

Como efeito, as pesquisas sobre a gerência da informação e do conhecimento começaram a despertar na Ciência da Informação nos anos 1990 (PINHEIRO, 2006) e foi se consolidando como uma tendência de pesquisa da área (MARTELETO, 2009) até ser considerada atualmente como uma subárea (ARAÚJO, 2014; 2017).

Antes de apresentarmos os conceitos de GI e GC, que permeiam as discussões neste relato, é preciso definir o que se entende por informação e por conhecimento. A informação é originada do vocábulo latino informatio, que designa a ação de informare, ou seja; dar forma ou moldar correspondendo a uma representação mental do mundo empírico. Para construção de uma informação se faz necessário envolver atividades de coleta, classificação e aglutinação de dados, seguindo um critério lógico, que possa conferir significado para se atingir um determinado objetivo.

De forma mais abrangente, a informação pode ser entendida como a materialização do conhecimento, independente do suporte que esteja representada. A construção do conhecimento, segundo Santos, Llarena e Lira (2014) ocorre quando acontecem ações físicas ou mentais sobre objetos, que ao provocarem desequilíbrios, resultam em acomodação e/ou assimilação dessas ações que levam a construção de esquemas ou conhecimento. $O$ equilíbrio entre assimilação e acomodação resulta em adaptação. Esse momento representa a ação do objeto sobre o sujeito e emerge como elemento das interações entre sujeito-objeto.

$\mathrm{Na}$ atualidade, Choo (2003) entende que todo negócio é um negócio de informação, sendo que esta é um recurso inerente a quase totalidade das atividades de uma organização. De acordo com o autor, as organizações usam estrategicamente a informação para: dar sentido às mudanças do ambiente externo, gerar novos conhecimentos por meio do aprendizado e tomar decisões importantes.

Percebemos que a informação e o conhecimento, em uma perspectiva organizacional são insumos indispensáveis e são construídos juntos, pelas condutas de gestão ou práticas organizacionais. Bettencourt e Cianconi (2012) conceituam o termo gestão como o ato de

Perspectivas em Gestão \& Conhecimento, João Pessoa, v. 10, número especial, p. 176-200, mar. 2020. 
administrar, orientar, conferir e avaliar as atividades ou ações de um grupo ou instituição que tem por finalidade alcançar seus objetivos.

Ao falarmos em Gl é preciso considerar que suas origens podem ser encontradas em trabalhos de autores como Paul Otlet, Vanevar Bush e Frederick Hayek que já se preocupavam com a informação e o conhecimento enquanto fenômenos relevantes do ponto de vista da produtividade pessoal e empresarial. Otlet, Bush e Hayek foram precursores da moderna GI, pois consideravam a informação e o conhecimento merecedores de esforços no sentido de seu efetivo gerenciamento (BARBOSA, 2008).

Para Monteiro e Duarte (2019) a GI tem seus indícios ou surgimento a partir da Documentação, por entender que esta última é uma disciplina responsável por desenvolver os primeiros instrumentos e técnicas para resolução dos problemas de excesso informacional.

Souza e Duarte (2011) compreendem que o surgimento da GI deve-se a necessidade da mediação da informação em diversas ciências que compreendem o seu campo. A informação e o trabalho desenvolvido por meio da gestão constituem o objeto de estudo da Biblioteconomia e da Ciência da Informação, sendo áreas que se transformam em produtos e serviços úteis para o usuário (TARAPANOFF, 2006).

No que se refere aos conceitos de GI, podemos entender como um processo dinâmico e cíclico de fases ou dimensões, com o intuito de possibilitar um eficiente fluxo de informação. Conforme Davenport (1998) a Gl é um conjunto de atividades que incluem o modo como as empresas obtêm, distribuem e usam a informação e o conhecimento, identificando o processo informacional que envolvem as fontes, as pessoas e os problemas a serem resolvidos.

A aplicação dos princípios da administração à aquisição, à organização, ao controle, à disseminação e ao uso da informação relevante para operar efetivamente as organizações de todos os tipos é conhecida por gestão da informação (WILSON, 2002). Para Valentim (2004) a GI pode ser considerada como um conjunto de estratégias que visa identificar as necessidades informacionais, mapear os fluxos formais de informação nos diferentes ambientes da organização, assim como sua coleta, filtragem, análise, organização, armazenagem e disseminação no ambiente corporativo.

A Gl é uma ação administrativa de um ambiente informacional, sendo um processo que obtém, processa e usa recursos basilares para direcionar a informação na organização e para servir a sociedade (PONJUÁN DANTE, 2004).

Para o entendimento dessas etapas, dimensões ou processos de gestão da informação nas organizações, existem modelos teóricos que permitem aplicações no âmbito das organizações. Destacam-se, por exemplo, o modelo de McGree e Prusak (1994), Davenport (1998) e Choo (2003) que apresentam a determinação de necessidades, de exigências e de requisitos de informação; aquisição, coleta, obtenção, organização, armazenamento, distribuição, classificação, tratamento e apresentação da informação; desenvolvimento de produtos e de serviços de informação; utilização/uso, disseminação e análise da informação.

No que se refere à GC, Araújo (2014) relata que a partir de trabalhos sobre a espiral do conhecimento de Nonaka e Takeuchi (1997); a ênfase na questão da aprendizagem de Senge (1998); dos princípios que regem a gestão do conhecimento de Davenport e Prusak (1998) e; do capital intelectual de Stewart (1998), Edvinsson e Malone (1998) é que foram surgindo a percepção dos processos de gestão do conhecimento.

Para que seja realizada a gestão do conhecimento, a organização deve construir estratégias ou práticas que possibilitem a conversão de dois tipos de conhecimento apresentados por Nonaka e Takeuchi (1997), a saber: os conhecimentos tácito e o explícito.

Para que a conversão do conhecimento tácito em explícito ocorra de modo que seja criado, compartilhado e utilizado, é preciso que as organizações criem um contexto

Perspectivas em Gestão \& Conhecimento, João Pessoa, v. 10, número especial, p. 176-200, mar. 2020. 
capacitante, em meio físico ou virtual, onde sejam efetivadas as interações baseadas na solicitude e na confiança entre as pessoas ou colaboradores.

Na literatura científica, vários teóricos abordam sobre o conceito de GC, mas podemos destacar um dos mais citados elaborado por Nonaka e Takeuchi (2008) ao apresentarem como processo de criar novos conhecimentos, disseminando-os por meio da organização e incorporando-os em novos produtos e/ou serviços, tecnologias e sistemas que perpetua a mudança no interior da organização.

Para Valentim (2004), gestão do conhecimento é um conjunto de estratégias para criar, adquirir, compartilhar e utilizar ativos de conhecimento, bem como estabelecer fluxos que garantam a informação necessária no tempo e formato adequados, a fim de auxiliar na geração de ideias, solução de problemas e tomada de decisão. Angeloni (2008, p. 2), considera a GC como "um conjunto de processos que governa a aquisição, a criação, o compartilhamento, o armazenamento e a utilização de conhecimento no âmago das organizações".

Amorim e Tomaél (2011, p. 8), afirmam que a GC é o principal objetivo das organizações, pois "[...] almejam melhor administrar seu capital intelectual e adotar medidas que controlem a criação de conhecimento organizacional." Para as autoras, a eficácia concretização da GC é realizada com a harmonia dos diversos aspectos organizacionais, que coordenados e bem administrados permitirá a implementação de um processo de gestão do conhecimento organizacional.

A partir desta perspectiva, percebe-se que GI e a GC focalizam aspectos complementares de dois importantes fenômenos organizacionais. Enquanto a GI focaliza a informação ou o conhecimento registrado, a GC destaca o conhecimento pessoal, muitas vezes tácito, e que, para ser efetivamente utilizado, precisa antes ser descoberto e socializado (BARBOSA, 2008).

A GI e a GC tornam-se imprescindíveis em qualquer organização e passíveis de serem aplicadas pelo profissional da informação no exercício de sua função e na sua responsabilidade social. No campo da administração das organizações, de uma maneira geral, o conhecimento é considerado um ativo intangível de valor inestimável e quando socialmente compartilhado pelo grupo é capaz de fazer entender e vencer as contingências ambientais.

No que se refere ao contexto do ensino e pesquisa sobre a GI e a GC, o profissional da informação no exercício de sua função pode atuar como gestor da informação e do conhecimento em qualquer organização, independentemente de ser pública, privada ou de terceiro setor. A pós-graduação em $\mathrm{Cl}$, por sua vez, deve assumir a responsabilidade de ofertar disciplinas para capacitar seus formandos para o desempenho de atividades que se apresentam como caminhos promissores.

\section{EVOLUÇÃO DA DISCIPLINA GESTÃO DA INFORMAÇÃO E DO CONHECIMENTO DOS CURRÍCULOS DA PÓS-GRADUAÇÃO EM CIÊNCIA DA INFORMAÇÃO NO BRASIL}

A pós-graduação no Brasil é estruturada a partir do Parecer no 977 CES/CFE, de 3 de dezembro de 1965, conhecido como Parecer Sucupira, instituído na reforma Universitária de 1965 quando a educação e o desenvolvimento científico estiveram atrelados a um projeto de governo dos militares que planejavam um modelo de ensino superior, de universidade e pósgraduação (ALVES; OLIVEIRA, 2014). Mas é somente em 1968, com a reforma do ensino superior, que se cria a pós-graduação nas universidades brasileiras, seguindo moldes norteamericanos (MARTELETO, 2009).

Perspectivas em Gestão \& Conhecimento, João Pessoa, v. 10, número especial, p. 176-200, mar. 2020. 
Com a ocorrência da reforma do ensino superior, a partir da década de 1970 que se inicia a expansão do sistema nacional de pós-graduação, essa expansão é estabelecida, segundo Marteleto (2009, p. 25), como:

[...] a qualificação dos quadros docentes e o desenvolvimento mais sustentados das atividades de pesquisa, no contexto de políticas educacionais e de ciência e tecnologia organizadas pelo Estado militarautoritário brasileiro, no quadro dos planos e metas para o desenvolvimento econômico e a construção da soberania nacional.

Em relação aos Programas de Pós-Graduação em Ciência da Informação (PPGCls), seu início é na década de 1970 com a implementação do Mestrado em Cl no Instituto Brasileiro de Bibliografia e Documentação (IBBD), em convênio com a Universidade Federal do Rio de Janeiro (UFRJ). Em 1976, o IBBD passa a ser chamado Instituto Brasileiro de Informação em Ciência e Tecnologia (IBICT) (PINHEIRO; LOUREIRO, 1995).

De acordo com Oddone (2005), a implementação do IBICT introduz um novo regime de informação no Brasil por causa de novas práticas e posturas que o órgão adotou e disseminou entre os bibliotecários e pesquisadores brasileiros e principalmente com a adoção de novas construções teóricas que começavam a ser utilizadas.

Conforme Souza, Dias e Nassif (2011, p. 57), a GI e a GC correspondem a uma área de conhecimento com contribuições de diversas áreas e/o campos do conhecimento, notadamente, da Administração, da Ciência da Computação, da Ciência da Informação e da Engenharia de Produção. Nesse sentido, Souza e Stumpf (2009) afirmavam que existiam, na época, 11 PPGCls e que em pesquisa realizada no portal da Coordenação de Aperfeiçoamento de Pessoal de Nível Superior (CAPES) algumas linhas de pesquisa selecionadas dos PPGCls já pertenciam ao eixo de Gestão da Informação com áreas temáticas gerenciais.

Os PPGCls estão localizados, conforme a classificação das áreas de conhecimento definida pelo CNPq como uma subárea das Ciências Sociais Aplicadas e Comunicação e Informação na CAPES. Conforme pesquisa de Brambilla (2007) a Cl compreende, inicialmente a: Biblioteconomia, Teoria da Informação, Processos de Comunicação, Representação da Informação, Teoria da Classificação, Métodos Quantitativos, Bibliometria, Técnicas de Recuperação de Informação, ente outros. Atualmente, na segunda década do século XXI, a área possui um vasto campo de tendências teóricas e suas subáreas, dentre elas, a Gestão da Informação e do Conhecimento (ARAúJO, 2014, 2017).

Os currículos dos PPGCls são compostos por disciplinas elencadas como obrigatórias e optativas centradas nas linhas de pesquisas nas quais estão inseridas. Os programas têm autonomia para estabelecer seus currículos, contanto que as disciplinas sejam compatíveis com as linhas de pesquisa. A pesquisa realizada por Brambilla (2007) apresenta análise dos conjuntos das disciplinas dos currículos do PPGCls, conforme o Quadro 1 a seguir:

Quadro 1 - Disciplinas dos PPGCls por categorias Temáticas

\begin{tabular}{|l|l|}
\hline Categorias da Pesquisa & Disciplinas dos PPGCls \\
\hline Categoria 1 - Fundamentos em Cl & 37 disciplinas \\
\hline Categoria 2 - Organização e Processamento da Informação & 24 disciplinas \\
\hline Categoria 3 - Gestão da Informação & 30 disciplinas \\
\hline Categoria 4 - Tecnologias da Informação & 18 disciplinas \\
\hline Categoria 5 - Transferência da Informação & 40 disciplinas \\
\hline Categoria 6 - Aplicações da Informação & 12 disciplinas \\
\hline Total & 160 disciplinas \\
\hline
\end{tabular}

Fonte: Brambilla (2007, p. 85)

Perspectivas em Gestão \& Conhecimento, João Pessoa, v. 10, número especial, p. 176-200, mar. 2020. 
Este estudo buscou analisar os temas e tendências curriculares que norteiam a pósgraduação em Cl. Para isso, Brambilla (2007) caracterizou todas as disciplinas dos PPGCls existentes na época. A análise das disciplinas identificadas nos programas apresenta seis (6) categorias temáticas. Entre as categorias apresentadas, a Gestão da Informação agrega 30 disciplinas que direcionam a tendência temática para os processos gerencias. Dessa forma, percebe-se que as disciplinas de gestão já estavam presentes nos PPGCls desde os anos finais do século XX e início do século XXI quando foi realizada a pesquisa.

As questões relacionadas à formação do profissional e cientistas da informação perpassam por capacitações práticas e teóricas que se reproduzem em: gestão da informação, tratamento da informação, tecnologia da informação, atendimento e interação com o usuário e as que afetam suas próprias atitudes e qualidades pessoais (SOUZA, 2006). Dessa forma, além da GI fazer parte da capacitação do profissional da informação, ela é apresentada como área abrangente da $\mathrm{Cl}$, conforme afirma Marchiori (2002, p. 75), a seguir:

[...] o enfoque da ciência da informação permite que se identifique a abrangência da gestão da informação. Como grande área, os conhecimentos, habilidades, teorias e metodologias da ciência da informação são utilizados e compartilhados por subáreas que, em geral, resultam em formações acadêmicas em nível técnico, de graduação e de pós-graduação.

Em relação à GC, em pesquisa realizada por Santos e Damian (2018), intitulada "Análise curricular da Gestão do Conhecimento em programas de pós-graduação em Ciência da Informação no Brasil", as autoras afirmam a partir das ementas selecionadas que os PPGCls têm presentes em suas estruturas curriculares os impactos da GC nos ambientes organizacionais e formas de implementação dessa gestão, apresentando temas relacionados com a GC como a gestão documental, gestão de arquivos e memória organizacional. Por fim, elas afirmam que alguns programas enfatizam a GC como produto da Sociedade da Informação e do Conhecimento que está diretamente relacionado às tendências da gestão da informação e do conhecimento.

Nessa perspectiva, todos os PPGCls abordam temas emergentes indiretamente relacionadas à GC no âmbito organizacional conectando com a inteligência competitiva, tecnologias e cultura organizacional. Com isso, para Santos e Damian (2018, p. 2), a Cl, que tem como objeto de estudo a informação, passou a "[...] estudar os vieses e eixos da GC, de modo que muitos programas de pós-graduação nessa área dispõem em sua estrutura curricular, disciplinas voltadas à gestão da informação e do conhecimento."

Além da evolução das disciplinas relacionas à GIC, registra-se a criação de cursos de pós-graduação específicos em Gestão da Informação e do Conhecimento, áreas de concentração e/ou como linhas de pesquisa em alguns Programas em Ciência da Informação. Destaca-se o relato recente de Nassif, Paula e Crivellari (2019) a respeito das origens, da trajetória e das perspectivas das pesquisas realizadas sobre o tema no âmbito da $\mathrm{PPGCl}$ da Universidade Federal de Minas Gerais.

Assim, cada programa tem sua responsabilidade em acompanhar a evolução temática da ciência e oferecer um amplo leque de possibilidades aos seus alunos, para auxiliálos nas atividades de pesquisa e no aprimoramento dos conhecimentos na área.

\section{PROCEDIMENTOS METODOLÓGICOS}

A pesquisa caracteriza-se, quanto ao objetivo, como exploratória e descritiva, no sentido de que procuramos descrever os conteúdos das disciplinas sobre Gl e GC ofertadas nos

Perspectivas em Gestão \& Conhecimento, João Pessoa, v. 10, número especial, p. 176-200, mar. 2020. 
cursos de pós-graduação em Ciência da Informação. Na visão de Prodanov e Freitas (2013), a pesquisa exploratória tem como finalidade proporcionar mais informações sobre o assunto que será investigado, possibilitando sua definição e seu delineamento. E é descritiva quando o pesquisador registra e descreve os fatos observados sem interferir neles.

Quanto à abordagem do problema é uma pesquisa quantitativa com tratamento estatístico simples em tabelas e qualitativa ao apresentar os conteúdos emergentes das disciplinas de GIC na pós-graduação em $\mathrm{Cl}$ em forma de quadros e figuras. Enquanto o estudo de abordagem quantitativa é amplo e com informações numéricas, a pesquisa qualitativa busca analisar e interpretar aspectos mais profundos (MARCONI; LAKATOS, 2011). O estudo é do tipo documental realizado no ambiente da web em relação às fontes de informações para coleta dos dados, tais como: Plataforma Sucupira (2019) do Ministério da Educação (MEC) e nos sites dos programas de pós-graduação em pauta.

A Plataforma Sucupira possibilitou a identificação das Universidades que disponibilizam a relação organizada dos cursos de pós-graduação em Ciência da Informação no Brasil. Nesse sentido, a pesquisa contemplou o universo de Instituições de Ensino Superior (IES) que oferecem cursos de pós-graduação em $\mathrm{Cl}$ considerando a necessidade de atingir uma análise mais ampla e resultados mais satisfatórios.

Para organização e análise dos dados foi adotado o método de análise de conteúdo proposto por Bardin (2011). A análise de conteúdo é considerada como um conjunto de técnicas para analisar as comunicações por meio de procedimentos sistemáticos e descrever os conteúdos das mensagens mediante indicadores que permitam a inferência de conhecimentos relativos às mensagens. A autora mencionada recomenda três fases para realização da análise de conteúdo: a) pré-análise; b) a exploração do material e, c) o tratamento dos resultados, a inferência e a interpretação.

A fase da pré-análise consistiu na sistematização das ideias iniciais correspondentes a escolha do documento da web que foi adotado como fonte de coleta de dados, a formulação do objetivo e a definição dos indicadores para possibilitar a interpretação final. A exploração do material consistiu na aplicação das decisões tomadas durante a fase de projeto de pesquisa. O tratamento dos resultados, a inferência e a interpretação consistiram na organização dos dados em quadros, tabelas e figuras, possibilitando assim, a análise do corpus e as considerações finais.

Como estratégia de ação para atingir o objetivo da pesquisa foram identificados os aspectos estruturais desta subárea nos Programas de pós-graduação, além das disciplinas intituladas do referido eixo-temático e da análise das suas ementas.

\section{RESULTADOS E DISCUSSÃO}

Para atender o objetivo desta pesquisa, foi necessária, inicialmente, a realização de uma consulta na Plataforma Sucupira para listar as IES que ofertam cursos de pós-graduação em $\mathrm{Cl}$. Após essa identificação foi possível coletar os dados necessários para o desenvolvimento deste estudo.

O Quadro 2 apresenta as IES federais que oferecem cursos de pós-graduação em Cl:

Quadro 2 - Instituições de Ensino Superior que oferecem cursos de Pós-Graduação em Cl

\begin{tabular}{|l|l|l|l|}
\hline \multicolumn{4}{|c|}{ Instituições de Ensino Superior } \\
\hline 1 & Fundação Casa de Rui Barbosa (FCRB) & 13 & Universidade Federal de Santa Catarina (UFSC) \\
\hline 2 & Universidade Federal de Sergipe (UFS) & 14 & Universidade Federal de São Carlos (UFSCAR) \\
\hline 3 & Universidade de Brasília (UNB) & 15 & Universidade Federal do Cariri (UFCA) \\
\hline 4 & Universidade de São Paulo (USP) & 16 & Universidade Federal do Ceará (UFC) \\
\hline 5 & Universidade do Estado de Santa Catarina & 17 & Universidade Federal do Espírito Santo (UFES) \\
\hline
\end{tabular}

Perspectivas em Gestão \& Conhecimento, João Pessoa, v. 10, número especial, p. 176-200, mar. 2020. 


\begin{tabular}{|c|c|c|c|}
\hline & (UDESC) & & \\
\hline 6 & Universidade Estadual de Londrina (UEL) & 18 & $\begin{array}{l}\text { Universidade Federal do Estado do Rio de } \\
\text { Janeiro (UNIRIO) }\end{array}$ \\
\hline 7 & $\begin{array}{l}\text { Universidade Estadual Paulista Júlio de } \\
\text { Mesquita Filho (UNESP) }\end{array}$ & 19 & Universidade Federal do Pará (UFPA) \\
\hline 8 & Universidade Federal da Bahia (UFBA) & 20 & Universidade Federal do Rio de Janeiro (UFRJ) \\
\hline 9 & Universidade Federal da Paraíba (UFPB) & 21 & $\begin{array}{l}\text { Universidade Federal do Rio Grande do Norte } \\
\text { (UFRN) }\end{array}$ \\
\hline 10 & Universidade Federal de Alagoas (UFAL) & 22 & $\begin{array}{l}\text { Universidade Federal do Rio Grande do Sul } \\
\text { (UFRGS) }\end{array}$ \\
\hline 11 & $\begin{array}{l}\text { Universidade Federal de Minas Gerais } \\
\text { (UFMG) }\end{array}$ & 23 & Universidade Federal Fluminense (UFF) \\
\hline 12 & $\begin{array}{l}\text { Universidade Federal de Pernambuco } \\
\text { (UFPE) }\end{array}$ & 24 & $\begin{array}{l}\text { Fundação Mineira de Educação e Cultura } \\
\text { (FUMEC) }\end{array}$ \\
\hline
\end{tabular}

Fonte: Dados da pesquisa (2019)

Mediante os dados expostos no Quadro 2 existem 24 IES que ofertam os cursos de pós-graduação em $\mathrm{Cl}$ em nível nacional. A Tabela 1 apresenta os cursos e seus níveis ofertados pelos programas de pós-graduação das IES:

Tabela 1 - Cursos de pós-graduação na área de Ciência da Informação

\begin{tabular}{l|l|l|l}
\hline Área & Cursos de pós-graduação & Frequência & \% \\
\hline \multirow{3}{*}{$\begin{array}{l}\text { Ciência da } \\
\text { informação }\end{array}$} & Mestrado Acadêmico & 19 & $47,5 \%$ \\
\cline { 2 - 4 } & Doutorado & 13 & $32,5 \%$ \\
\cline { 2 - 4 } & Mestrado Profissional & 08 & $\mathbf{2 0 \%}$ \\
\cline { 2 - 4 } & Total & $\mathbf{4 0}$ & $\mathbf{1 0 0 \%}$ \\
\hline
\end{tabular}

Fonte: Dados da pesquisa (2019)

Foi constatado que existem 40 (100\%) cursos de pós-graduação em Cl. Com a obtenção da quantidade de cursos e seus níveis, observamos que o maior percentual dos cursos de pós-graduação corresponde ao nível de mestrado acadêmico com 47,5\%. Em seguida, o doutorado correspondendo a $32,5 \%$. E por fim, o mestrado profissional que com $20 \%$ dos cursos.

\subsection{Instituições, programas e notas (conceitos)}

A avaliação dos cursos de mestrado acadêmico, mestrado profissional e doutorado nos programas de pós-graduação vem sendo realizada periodicamente. Ela gera notas que vão de um a sete. Os programas são avaliados baseados em conceitos atribuídos que variam em muito bom, bom, regular, fraco e insuficiente. A partir desses conceitos, as notas são atribuídas. Com a identificação das IES e dos programas por meio da plataforma Sucupira (2019), foi possível obter as notas atribuídas a cada programa em Cl das IES.

No primeiro momento verificamos a frequência dos programas de pós-graduação, conforme a Tabela 2:

Perspectivas em Gestão \& Conhecimento, João Pessoa, v. 10, número especial, p. 176-200, mar. 2020. 
Tabela 2 - Programas de Pós-Graduação

\begin{tabular}{l|l|l}
\hline Programas & Frequência & $\%$ \\
\hline Ciência da Informação & 16 & 59,2 \\
\hline Ciências da Informação & 2 & 7,5 \\
\hline Gestão da Informação & 2 & 7,5 \\
\hline Biblioteconomia & 2 & 7,5 \\
\hline Gestão \& Organização do Conhecimento & 1 & 3,7 \\
\hline Memória e Acervos & 1 & 3,7 \\
\hline Gestão de Documentos e Arquivos & 1 & 3,7 \\
\hline Gestão da Informação e do Conhecimento & 1 & 3,7 \\
\hline Sistema de Informação e Gestão do Conhecimento & 1 & 3,7 \\
\hline Total & $\mathbf{2 7}$ & $\mathbf{1 0 0 \%}$ \\
\hline Fonte: Dados da pesquisa (2019) &
\end{tabular}

Fonte: Dados da pesquisa (2019)

Existem 27 (100\%) programas de pós-graduação na área de $\mathrm{Cl}$. Os intitulados como Ciência da Informação correspondem a 59,2\% do total. Os programas que correspondem a 7,5\% são os seguintes: Ciências da Informação, Gestão da Informação e, Biblioteconomia. Correspondendo a 3,7\% estão os programas: Memória e Acervos; Gestão \& Organização do Conhecimento; Gestão de Documentos e Arquivos; Gestão da Informação e do Conhecimento; e Sistemas de Informação e Gestão do Conhecimento.

Em seguida, no Quadro 3, são apresentadas as notas atribuídas a cada programa.

Quadro 3 - Instituições, Programas e Notas

\begin{tabular}{|c|l|l|c|}
\hline \multicolumn{2}{|l|}{ IES } & $\begin{array}{l}\text { Denominação dos Programas } \\
\text { de Pós-Graduação }\end{array}$ & Notas \\
\hline 1 & Fundação Casa de Rui Barbosa (FCRB) & Memória e acervos (MA) & 3 \\
\hline 2 & Universidade Federal de Sergipe (FUFSE) & Ciência da Informação (CI) & 3 \\
\hline 3 & Universidade de Brasília (UNB) & Ciências da informação (CI) & 5 \\
\hline 4 & Universidade de São Paulo (USP) & Ciência da Informação (CI) & 4 \\
\cline { 3 - 4 } & & Gestão da Informação (GI) & 4 \\
\hline 5 & Universidade do Estado de Santa Catarina (UDESC) & Gestão da informação (GI) & 3 \\
\hline 6 & Universidade Estadual de Londrina (UEL) & Ciência da Informação (CI) & 4 \\
\hline 7 & Universidade Estadual Paulista "Júlio de Mesquita & Ciência da Informação (CI) & 6 \\
\hline 8 & Universidade Federal da Bahia (UFBA) & & 4 \\
\hline 9 & Universidade Federal da Paraíba (UFPB) & Ciência da Informação (CI) & 4 \\
\hline 10 & Universidade Federal de Alagoas (UFAL) & Ciência da Informação (CI) & 4 \\
\hline 11 & Universidade Federal de Minas Gerais (UFMG) & Ciência da Informação (CI) & A \\
\hline & & Ciências da Informação (Cl) & 5 \\
\cline { 2 - 4 } & & Gestão \& Organização do & 5 \\
\hline 12 & Universidade Federal de Pernambuco (UFPE) & Conhecimento (GOC) & \\
\hline 13 & Universidade Federal de Santa Catarina (UFSC) & Ciência da Informação (CI) & 5 \\
\hline 14 & Universidade Federal de São Carlos (UFSCAR) & Ciência da Informação (Cl) & 3 \\
\hline 15 & Universidade Federal do Cariri (UFCA) & Biblioteconomia (Biblio.) & 3 \\
\hline 16 & Universidade Federal do Ceará (UFC) & Ciência da Informação (Cl) & 3 \\
\hline 17 & Universidade Federal do Espírito Santo (UFES) & Ciência da Informação (Cl) & A \\
\hline 18 & Universidade Federal do Estado do Rio de Janeiro & Biblioteconomia (Biblio.) & 3 \\
\hline
\end{tabular}

Perspectivas em Gestão \& Conhecimento, João Pessoa, v. 10, número especial, p. 176-200, mar. 2020. 


\begin{tabular}{|c|l|l|c|}
\hline & (UNIRIO) & $\begin{array}{l}\text { Gestão de documentos e } \\
\text { arquivos (GDA) }\end{array}$ & 3 \\
\hline 19 & Universidade Federal do Pará (UFPA) & Ciência da Informação (CI) & 3 \\
\hline 20 & Universidade Federal do Rio de Janeiro (UFRJ) & Ciência da Informação (CI) & 4 \\
\hline 21 & $\begin{array}{l}\text { Universidade Federal do Rio Grande do Norte } \\
\text { (UFRN) }\end{array}$ & $\begin{array}{l}\text { Gestão da Informação e do } \\
\text { Conhecimento (GIC) }\end{array}$ & 3 \\
\hline 22 & Universidade Federal do Rio Grande do Sul (UFRGS) & Ciência da Informação (CI) & $\mathrm{A}$ \\
\hline 23 & Universidade Federal Fluminense (UFF) & Ciência da Informação (Cl) & 4 \\
\hline 24 & $\begin{array}{l}\text { Universidade Fundação Mineira de Educação e } \\
\text { Cultura (FUMEC) }\end{array}$ & $\begin{array}{l}\text { Sistema de Informação e } \\
\text { Gestão do Conhecimento } \\
\text { (SIGC) }\end{array}$ & 4 \\
\hline
\end{tabular}

Fonte: Dados da pesquisa (2019)

No Quadro 3, a nota 6, mais alta, foi atribuída à UNESP. Os programas que possuem nota 5 são os da UNB e UFSC, além dos programas de Ciências da Informação e Gestão \& Organização do Conhecimento da UFMG.

A nota 4 foi atribuída aos programas de Ciência da Informação e GI da USP, aos programas de Ciência da Informação da UEL, UFBA, UFPB, UFPE, UFRJ, UFF e ao programa de Sistema de Informação e Gestão do Conhecimento da FUMEC.

A nota 3 foi atribuída aos Programas de pós-graduação em Memórias e Acervos da FCRB, ao programa de GI da UDESC, ao programa de Biblioteconomia da UFCA, aos programas de Biblioteconomia e Gestão de documentos e arquivos da UNIRIO, ao programa de Gestão da Informação e do Conhecimento da UFRN e aos programas da UFSE, UFSCAR, UFC e UFPA. O conceito " $A$ " é determinado aos novos cursos (UFAL, UFES e UFRGS) na Plataforma Sucupira.

A importância de identificar as notas atribuídas diz respeito à verificação da validação ou não dos programas de pós-graduação que disponibilizam as disciplinas utilizadas para caracterização e obtenção do objetivo deste relato. As notas 3 a 5 valem respectivamente aos conceitos "regular", "bom" e "muito bom". Além disso, há também os conceitos 6 e 7, que expressam excelência constatada em nível nacional. Somente os programas que têm doutorado podem aspirar as notas 6 e 7 .

Foi possível verificar que a Gestão da Informação e a Gestão do Conhecimento são temas que vêm sendo ofertados em parte dos programas, apresentando conceitos (notas) entre bom e muito bom e que oferecem conteúdos inovadores para a formação dos alunos de pós-graduação.

\subsection{Linhas de pesquisa}

As linhas de pesquisa caracterizam as temáticas norteadoras ou indicadores de pesquisas dos programas de pós-graduação. No caso da $\mathrm{Cl}$, visam contribuir com a pesquisa científica, formação de docentes (mestrados acadêmicos e doutorado) e qualificação de profissionais (mestrado profissional). No Quadro 4, a seguir, apresentamos as que fazem parte dos programas em Cl no Brasil:

Perspectivas em Gestão \& Conhecimento, João Pessoa, v. 10, número especial, p. 176-200, mar. 2020. 
Quadro 4 - Linhas de pesquisa

\begin{tabular}{|c|c|c|}
\hline \multicolumn{2}{|c|}{$\begin{array}{l}\text { Instituições/ } \\
\text { programas }\end{array}$} & \multirow{2}{*}{$\begin{array}{l}\text { Linhas de pesquisa } \\
\text { Patrimônio documental: representação, gerenciamento e preservação de } \\
\text { espaços de memória; Produção, Organização e Comunicação da Informação. }\end{array}$} \\
\hline 1 & FCRB/MA & \\
\hline 2 & UFSE/Cl & $\begin{array}{l}\text { Informação, Sociedade e Cultura; Produção, Organização e Comunicação da } \\
\text { Informação }\end{array}$ \\
\hline 3 & $\mathrm{UNB} / \mathrm{Cl}$ & Organização da Informação; Comunicação e Mediação da Informação \\
\hline 4 & USP/Cl & $\begin{array}{l}\text { Gestão de dispositivos de informação; Apropriação social da informação; } \\
\text { Organização da informação e do conhecimento }\end{array}$ \\
\hline 5 & USP/GI & $\begin{array}{l}\text { Gestão de unidades de informação; Mediação cultural; Organização do } \\
\text { conhecimento }\end{array}$ \\
\hline 6 & UDESC/GI & Informação, memória e sociedade; Gestão de unidades de informação \\
\hline 7 & UEL/GI & $\begin{array}{l}\text { Compartilhamento da informação e do conhecimento; Organização e } \\
\text { representação da informação e do conhecimento }\end{array}$ \\
\hline 8 & UNESP/Cl & $\begin{array}{l}\text { Gestão, Mediação e Uso da Informação; Informação e Tecnologia; Produção e } \\
\text { Organização da informação }\end{array}$ \\
\hline 9 & UFBA/CI & $\begin{array}{l}\text { Políticas e Tecnologias da Informação; Produção, Circulação e Mediação da } \\
\text { Informação }\end{array}$ \\
\hline 10 & UFPB/Cl & $\begin{array}{l}\text { Ética, gestão e Política de Informação; Informação, Memória e Sociedade; } \\
\text { Organização, Acesso e Uso da Informação }\end{array}$ \\
\hline 11 & UFAL/CI & $\begin{array}{l}\text { Informação, Comunicação e Processos Tecnológicos; Produção, Mediação e } \\
\text { Gestão da Informação }\end{array}$ \\
\hline 12 & UFMG/Cl & $\begin{array}{l}\text { Memória social, patrimônio e produção do conhecimento; Políticas públicas e } \\
\text { organização da informação e Usuários, gestão do conhecimento e práticas } \\
\text { informacionais. }\end{array}$ \\
\hline 13 & UFMG/ GOC & Arquitetura \& Organização do Conhecimento; Gestão \& Tecnologia \\
\hline 14 & UFPE/CI & $\begin{array}{l}\text { Memória da Informação Científica e Tecnológica; Comunicação e Visualização } \\
\text { da Memória }\end{array}$ \\
\hline 15 & $\mathrm{UFSC} / \mathrm{Cl}$ & $\begin{array}{l}\text { Organização, Representação e Mediação da Informação e do Conhecimento; } \\
\text { Informação, Gestão e Tecnologia }\end{array}$ \\
\hline 16 & UFSCAR/CI & $\begin{array}{l}\text { Conhecimento e Informação para Inovação; Tecnologia, Informação e } \\
\text { Representação }\end{array}$ \\
\hline 17 & UFCA/Biblio. & Informação, Cultura e Memória; Produção, Comunicação e Uso da Informação \\
\hline 18 & $\mathrm{UFC} / \mathrm{Cl}$ & $\begin{array}{l}\text { Mediação e Gestão da Informação e do Conhecimento; Representação da } \\
\text { Informação e do Conhecimento e Tecnologia }\end{array}$ \\
\hline 19 & UFES/Cl & $\begin{array}{l}\text { Informação, Sociedade e Cultura; Produção, Organização e Comunicação da } \\
\text { Informação }\end{array}$ \\
\hline 20 & UNIRIO/Biblio. & $\begin{array}{l}\text { Organização e Representação do Conhecimento; Biblioteconomia, Cultura e } \\
\text { Sociedade }\end{array}$ \\
\hline 21 & UNIRIO/GDA & Gestão da Informação Arquivística; Arquivos, Arquivologia e Sociedade \\
\hline 22 & UFPA/Cl & Mediação e Uso da Informação; Organização da Informação \\
\hline 23 & UFRJ/Cl & $\begin{array}{l}\text { Comunicação, Organização e Gestão da Informação e do Conhecimento; } \\
\text { Configurações Socioculturais, Políticas e Econômicas da Informação }\end{array}$ \\
\hline 24 & UFRN/GIC & Gestão da Informação e do Conhecimento \\
\hline 25 & UFRGS/Cl & Informação e Ciência; Informação e Sociedade \\
\hline 26 & UFF/Cl & $\begin{array}{l}\text { Informação, Cultura e Sociedade; Fluxos e Mediações Sociotécnica da } \\
\text { Informação }\end{array}$ \\
\hline 27 & FUMEC/ SIGC & $\begin{array}{l}\text { Gestão da Informação e do conhecimento; Tecnologia em Sistemas de } \\
\text { Informação }\end{array}$ \\
\hline
\end{tabular}

Fonte: Dados da pesquisa (2019)

Perspectivas em Gestão \& Conhecimento, João Pessoa, v. 10, número especial, p. 176-200, mar. 2020. 
Foi possível analisar as linhas de pesquisa dispostas no Quadro 4 e suas características apresentadas na Plataforma Sucupira (2019) e nos sites dos programas em análise. Inicialmente, é preciso observar que apesar de ser uma temática relacionada à subárea 'Representação e Recuperação da Informação' (ARAÚJO, 2014), a linha de pesquisa Organização da Informação do Programa em Ciências da Informação da UnB contempla, surpreendentemente, indicadores de estudos e pesquisas na área de gestão da informação e do conhecimento e, inteligência competitiva.

Existem duas linhas de pesquisa em 'Gestão de Unidades de Informação' expostas nos dados elencados que, mesmo não apresentadas especificamente as condutas gerenciais de informação e conhecimento em seus termos, fazem parte de mestrados profissionais em GI da USP e UDESC.

Os dados sobre as linhas de pesquisa demonstram uma forte relação da GI e da GC com a 'mediação da informação' nos programas da UNESP, UFAL e UFC. Essa afinidade diz respeito ao encontro dos estudos teóricos e metodológicos de objetos e fenômenos que utilizam a gestão, a mediação, o uso e apropriação da informação em diferentes ambientes (VALENTIM, 2010).

Nas demais linhas de pesquisa, a GI e a GC estão relacionadas com a gestão, o compartilhamento de informação e conhecimento, a ética, a política, os fluxos informacionais, a tecnologia e com a inovação em distintos ambientes organizacionais, como é o caso do contexto da 'Gl na Arquivística'. Esses indicadores de pesquisas podem proporcionar uma integração entre as novas condutas teóricas de GIC, nesta área de conhecimento.

Verificamos que existem 15 linhas de pesquisa que contemplam abordagens direcionadas à Gl e/ou GC. Isso representa que os temas aglutinadores de estudos científicos que se fundamentam em tradição investigativa das linhas de pesquisa têm como base a Gl e a GC para produzirem projetos cujos resultados contribuirão para o desenvolvimento da ciência e da gestão como um todo.

As demais instituições possuem programas com linhas de pesquisa de diversos eixos temáticos dos quais se originam estudos e projetos de pesquisa resultantes da experiência dos docentes e das atividades dos grupos de pesquisa.

\subsection{Disciplinas relacionadas à Gestão da Informação e do Conhecimento}

Nesta fase, foram caracterizadas no Quadro 5, as disciplinas no contexto da GI, GC ou GIC como eixo temático dos programas de pós-graduação em $\mathrm{Cl}$. Estes, na maioria, denominam-se de Ciência da Informação, conforme Quadro 3. E suas linhas de pesquisa são pertinentes à abordagem da GIC, que vem sendo ofertadas nos níveis de mestrado e doutorado.

Quadro 5 - Disciplinas ofertadas e relacionadas à GIC

\begin{tabular}{|l|l|}
\hline $\begin{array}{l}\text { Instituições/ } \\
\text { programas }\end{array}$ & Disciplinas \\
\hline FCRB/MA & Arquivos e Bibliotecas em Ambiente Digital; Gestão museológica \\
\hline UFSE/CI & $\begin{array}{l}\text { Sistemas de informação aplicados à GI; Tópicos especiais em GIC; GIC em } \\
\text { acervos arquivísticos e documentais; Metodologia da pesquisa em CI e GIC; } \\
\text { Fundamentos em Cl e GIC; Gestão estratégica de unidades de informação; } \\
\text { Gestão do patrimônio informacional e proteção do conhecimento; Mercado de } \\
\text { trabalho e o gestor da informação e do conhecimento; Letramento } \\
\text { informacional na educação básica; Políticas públicas e competência } \\
\text { informacional }\end{array}$ \\
\hline
\end{tabular}

Perspectivas em Gestão \& Conhecimento, João Pessoa, v. 10, número especial, p. 176-200, mar. 2020. 


\begin{tabular}{|c|c|}
\hline $\mathrm{UNB} / \mathrm{Cl}$ & $\begin{array}{l}\text { Gestão do Conhecimento; Abordagem conversacional da Gestão Ontológica da } \\
\text { Informação e do Conhecimento; Seminário em Organização da Informação: } \\
\text { Sistemas de Inteligência Competitiva; Seminários em organização da } \\
\text { informação: inteligência organizacional e competitiva; Tópicos Especiais em } \\
\text { Organização da Informação: gestão da informação, gestão do conhecimento e } \\
\text { inteligência competitiva }\end{array}$ \\
\hline \multirow[t]{2}{*}{ USP/Cl-GI } & $\begin{array}{l}\text { Gestão da informação e do conhecimento; Planejamento e gestão de serviços } \\
\text { de informação especializados: reflexões teórico-metodológicas; Gestão de } \\
\text { conteúdos e recuperação da informação }\end{array}$ \\
\hline & Mediação cultural: teoria e prática; Circuitos culturais e mediação \\
\hline UDESC/GI & $\begin{array}{l}\text { Ética na Gestão da Informação; Tópicos Avançados em Gestão da Informação; } \\
\text { Tópicos avançados em gestão da informação: gestão de pessoas; Tópicos } \\
\text { avançados em gestão da informação: introdução à análise de domínio; Tópicos } \\
\text { avançados em gestão da informação: competência em informação na gestão de } \\
\text { unidades de informação; Tópicos avançados em gestão da informação: } \\
\text { evolução e estrutura da pesquisa científica; Tópicos avançados em gestão da } \\
\text { informação: biblioteca escolar; Tópicos avançados em gestão da informação: } \\
\text { multiculturalismo em gestão da informação; Tópicos avançados em gestão da } \\
\text { informação: preservação digital }\end{array}$ \\
\hline UEL/GI & $\begin{array}{l}\text { Tópicos especiais em } \mathrm{Cl} \text { : introdução a GC; Tópicos especiais em } \mathrm{Cl} \text { : organização, } \\
\text { acesso e apropriação da informação e do conhecimento; Comportamento e } \\
\text { competência informacionais }\end{array}$ \\
\hline UNESP/Cl & $\begin{array}{l}\text { Aspectos influenciadores da GC em contextos Organizacionais; Cultura } \\
\text { organizacional e comportamento organizacional para a GC nas organizações; } \\
\text { Cultura informacional e saber local: construindo competências para o } \\
\text { desenvolvimento regional sustentável; Cultura organizacional, sociedade e } \\
\text { sistemas de informação; Gestão de pessoas, aprendizagem organizacional e } \\
\text { competência em informação: novas condutas na sociedade contemporânea; } \\
\text { Políticas de preservação da memória e conhecimento organizacional: interfaces } \\
\text { com a GC; Informação, conhecimento e inteligência organizacional; Gestão do } \\
\text { conhecimento: tecnologias de preservação da memória; Métodos de pesquisa } \\
\text { aplicados à gestão, mediação e uso da informação; A cultura informacional na } \\
\text { ciência da informação: aspectos teóricos e práticos; Aspectos influenciadores } \\
\text { da gestão do conhecimento nas organizações; A cultura informacional na } \\
\text { ciência da informação: aspectos teóricos e práticos }\end{array}$ \\
\hline UFBA/Cl & Informação e Gestão do Conhecimento \\
\hline UFPB/Cl & $\begin{array}{l}\text { Cultura Informacional; Gestão: Informação, Conhecimento e Inteligência } \\
\text { Organizacional; Ética, gestão e políticas de informação; Conhecimento } \\
\text { organizacional; Gerenciamento estratégico da informação; Gestão da } \\
\text { informação e do conhecimento nas organizações }\end{array}$ \\
\hline UFAL/Cl & $\begin{array}{l}\text { Competência em Informação e Inovação; Gestão Estratégica de Unidades de } \\
\text { Informação; Produção Colaborativa da Informação e do Conhecimento; Gestão } \\
\text { Estratégica da Informação e do Conhecimento; Sistemas e Redes de } \\
\text { Colaboratividade }\end{array}$ \\
\hline \multirow[t]{2}{*}{ UFMG/Cl-GOC } & $\begin{array}{l}\text { Gestão da informação e do conhecimento: teorias e métodos; Tópicos em } \\
\text { informação, cultura e sociedade; Tópicos em gestão da informação e do } \\
\text { conhecimento; Gestão da informação e do conhecimento }\end{array}$ \\
\hline & $\begin{array}{l}\text { Inteligência e Gestão do Conhecimento; Gestão da Informação e do } \\
\text { Conhecimento em Ambientes Especiais; Tópicos especiais em gestão \& } \\
\text { tecnologia III; A prática da gestão da informação }\end{array}$ \\
\hline UFPE/Cl & Gestão de Processos e Serviços Informacionais \\
\hline $\mathrm{UFSC} / \mathrm{Cl}$ & $\begin{array}{l}\text { Organização do Conhecimento e Gestão Documental; Competência em } \\
\text { informação; Gestão de serviços informacionais; Tópicos especiais: gestão da }\end{array}$ \\
\hline
\end{tabular}

Perspectivas em Gestão \& Conhecimento, João Pessoa, v. 10, número especial, p. 176-200, mar. 2020. 


\begin{tabular}{|c|c|}
\hline & $\begin{array}{l}\text { informação para governança corporativa em segurança pública; Marketing e } \\
\text { estudos de usuários da informação; Informação, comunicação e práticas } \\
\text { culturais contemporâneas }\end{array}$ \\
\hline UFSCAR/Cl & Gestão da inovação; Gestão de processos e pessoas por competência \\
\hline UFCA/Biblio. & $\begin{array}{l}\text { Gestão da informação e do Conhecimento e inteligência competitiva em } \\
\text { Ambientes de informação; Políticas culturais em ambientes de informação }\end{array}$ \\
\hline $\mathrm{UFC} / \mathrm{Cl}$ & $\begin{array}{l}\text { Gestão da Informação e do Conhecimento; Gestão da Informação científica e } \\
\text { tecnologia; Informação social e cultura informacional; Cultura e mediação da } \\
\text { informação }\end{array}$ \\
\hline UFES/Cl & Competência em Informação \\
\hline UNIRIO/Biblio/GDA & $\begin{array}{l}\text { Tópicos Especiais em Gestão da Informação Arquivística } 1 \text { e 2; Arquivologia e } \\
\text { gestão }\end{array}$ \\
\hline UFPA/Cl & Não apresenta \\
\hline UFRJ/Cl & $\begin{array}{l}\text { Gestão da Informação nas Organizações; Gestão da Informação para Produção } \\
\text { de Conhecimento; Gestão da Informação e do Conhecimento; Estruturas e } \\
\text { fluxos da informação para produção e uso do conhecimento; Cultura, natureza } \\
\text { e informação; Estrutura e fluxos da informação; Gestão do conhecimento; } \\
\text { Informação e conhecimento na gestão estratégica }\end{array}$ \\
\hline UFRN/GIC & $\begin{array}{l}\text { Gestão da Informação e do Conhecimento; Metodologia da Pesquisa Aplicada à } \\
\text { Gestão da Informação e do Conhecimento; Informação, Organizações e } \\
\text { Processos; Estudo do comportamento informacional; Tópicos avançados em } \\
\text { gestão da informação e do conhecimento; Sistemas de informação gerenciais; } \\
\text { Inteligência de negócios e competitiva }\end{array}$ \\
\hline UFRGS/Cl & Redes Sociais na Ciência \\
\hline $\mathrm{UFF} / \mathrm{Cl}$ & $\begin{array}{l}\text { A gestão de ativos de informação e de conhecimento e a cultura organizacional; } \\
\text { Tópicos em comunicação, gestão, tecnologia e uso da informação I; Gestão de } \\
\text { ativos organizacionais de informação e de conhecimento }\end{array}$ \\
\hline FUMEC/ SIGC & $\begin{array}{l}\text { Gestão do Conhecimento; Capital intelectual; Inteligência competitiva; } \\
\text { Aprendizagem organizacional; Gestão de inovação tecnológica; Tópicos } \\
\text { especiais em gestão da informação e do conhecimento; Estudos especiais em } \\
\text { GIC; Interdisciplinaridade em sistemas de informação e gestão do } \\
\text { conhecimento; Tópicos especiais: a internet das coisas na gestão da informação }\end{array}$ \\
\hline
\end{tabular}

Fonte: Dados da pesquisa (2019)

A caracterização das disciplinas foi fundamental para conhecermos os eixos temáticos que elas abordam e se alguns estão relacionados com a Gl e/ou GC. Entre as 24 universidades que ofertam cursos de pós-graduação em Ciência da Informação, 16 adotam em suas áreas de concentração a palavra 'conhecimento' em uma demonstração de que a relação com a informação está integrada. Para Choo (2003) a relação integrada da informação com o conhecimento diz respeito como as organizações usam a informação para criar significado e assim construir conhecimento para a tomada de decisões nas organizações. $O$ autor debate sobre o uso da informação num contexto holístico, na qual analisa e compara as principais formas pelas quais uma organização usa a informação estrategicamente, de maneira que tenha sentido, para estabelecer uma mudança no ambiente.

Na visão de Choo (2003) existem três modos do uso da informação: interpretação, conversão e processamento da informação. Esses resultam em três ações: criação de significado, construção do conhecimento e tomada de decisões que objetivam a melhoria dos processos organizacionais. E assim, quando uma organização conseguir integrar de maneira efetiva e inteligente esses processos, poderá ser considerada uma organização do conhecimento.

Perspectivas em Gestão \& Conhecimento, João Pessoa, v. 10, número especial, p. 176-200, mar. 2020. 
Em relação à inclusão do eixo-temático pertinente, destacam-se 19 entre as 24 IES e os 27 programas. Como podemos observar, os programas com abordagens sobre $\mathrm{Gl}$ e $\mathrm{GC}$ são os seguintes: UNESP/Cl; UFMG/CI-GOC; UDESC/GI; UFRJ/Cl; UFSE/Cl; UNB/Cl; UFAL/Cl; UFRN/GIC; UFPB/Cl; UFC/Cl; $\mathrm{FUMEC/SIGC;} \mathrm{UFSC/Cl;} \mathrm{USP/Cl-GI;} \mathrm{UFBA/Cl;} \mathrm{UFCA/Biblio.;} \mathrm{UFSCar/Cl;}$ UFES/Cl; UEL/GI; UFF/Cl, conforme Tabela 3:

Tabela 3 - Programas que possuem as disciplinas sobre GI e/ou GC

\begin{tabular}{l|c|c}
\hline IES/Programas & Frequência & Percentual \% \\
\hline UNESP/Cl & 12 & $14,6 \%$ \\
\hline FUMEC/ SIGC & 9 & $11 \%$ \\
\hline UFSE/Cl & 7 & $8,5 \%$ \\
\hline UFMG/Cl-GOC & 7 & $8,5 \%$ \\
\hline UFPB/Cl & 6 & $7,3 \%$ \\
\hline UFRJ/Cl & 6 & $7,3 \%$ \\
\hline UNB/Cl & 5 & $6,1 \%$ \\
\hline UFAL/Cl & 5 & $6,1 \%$ \\
\hline UDESC/GI & 4 & $4,8 \%$ \\
\hline UFRN/GIC & 4 & $4,8 \%$ \\
\hline USP/Cl-GI & 3 & $3,7 \%$ \\
\hline UEL/GI & 3 & $3,7 \%$ \\
\hline UFSCAR/Cl & 2 & $2,5 \%$ \\
\hline UFCA/Biblio. & 2 & $2,5 \%$ \\
\hline UFC/Cl & 2 & $2,5 \%$ \\
\hline UFF/Cl & 2 & $2,5 \%$ \\
\hline UFBA/Cl & 1 & $1,2 \%$ \\
\hline UFSC/Cl & 1 & $1,2 \%$ \\
\hline UFES/Cl & 1 & $1,2 \%$ \\
\hline Total - 19 & Total - 82 & $100 \%$ \\
\hline Fonte: Dados & & \\
\hline
\end{tabular}

Fonte: Dados da pesquisa (2019)

Verificamos que as disciplinas fazem parte do eixo-temático da Gl e/ou GC. Das 19 instituições elencadas, dez (10) se destacaram em relação a incidência de disciplina sobre a GI e a GC. Entre estas, destacam-se: UNESP/Cl; UFMG/Cl-GOC; UDESC/GI; UFRJ/Cl; UFSE/Cl; UNB/Cl; FUMEC/SIGC; UFSC/Cl; UFPB/Cl; UFRN/GIC.

Existem programas que apesar de não abordarem diretamente os temas da GI ou GC, seus conteúdos têm relação com a Gestão em si, como: FCRB/MA; UFPE/Cl; UFRGS/Cl; UNIRIO/Biblio. - GDA; UFSCAR/CI, com exceção da UFPA/CI.

É possível tomar como inferência que as disciplinas de Gl e GC presentes nos cursos de pós-graduação em $\mathrm{Cl}$ estão, acentuadamente, nos programas positivamente avaliados/conceituados e nos mais recentes, que implicam em visão futura inovadora para esta área e podem ser representadas pela Figura 1:

Perspectivas em Gestão \& Conhecimento, João Pessoa, v. 10, número especial, p. 176-200, mar. 2020. 
Figura 1 - Representação em nuvem de tags das disciplinas em Gl e GC na pós-graduação em Cl

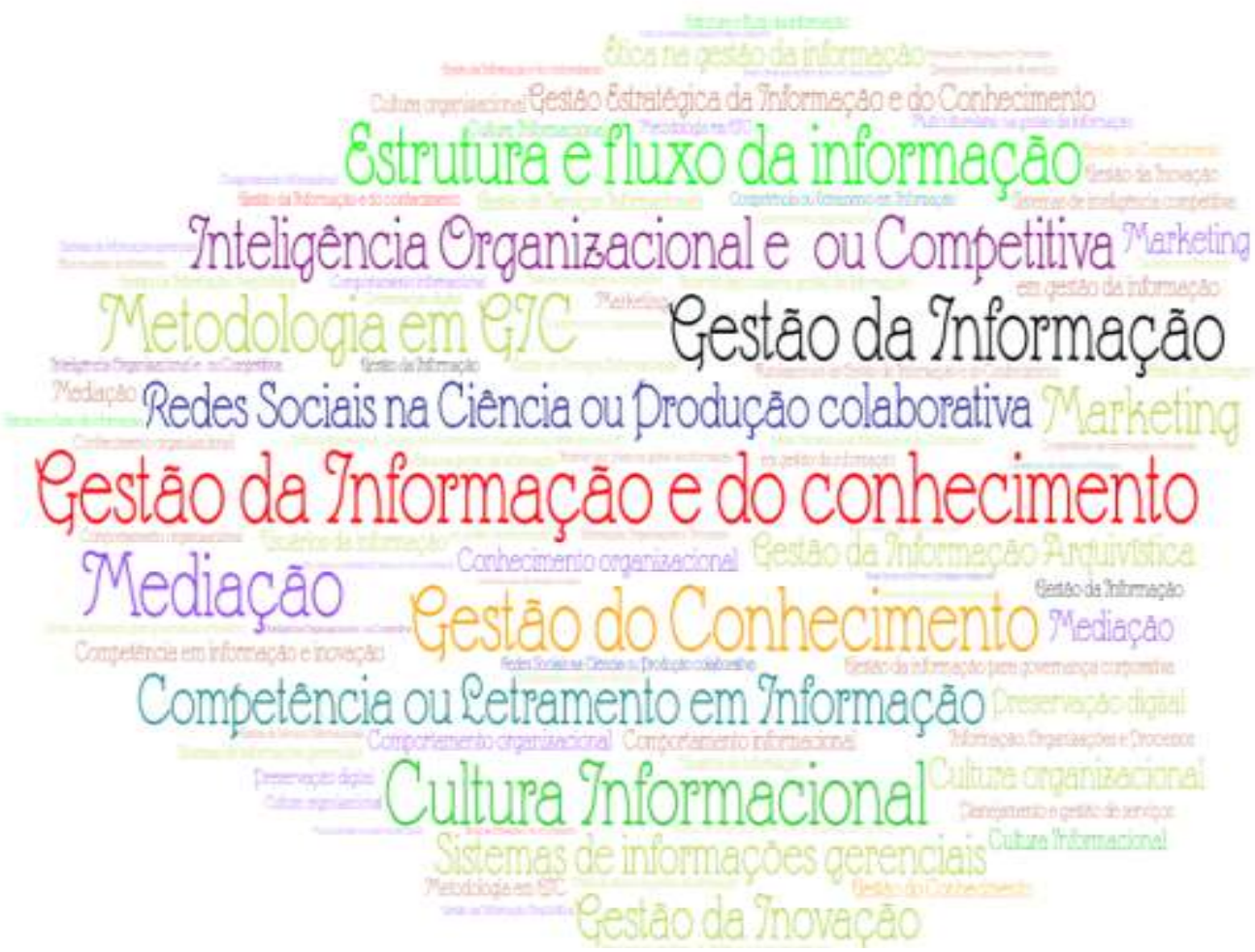

Fonte: Elaborado pelos autores (2019)

A nuvem de tags possibilita inferir que os resultados obtidos com a caracterização das disciplinas apresentam perspectivas positivas em relação as abordagens que estão sendo inseridas nos cursos. Isso significa o aprimoramento dos conteúdos programáticos de $\mathrm{Gl}$ e da GC adequados à Sociedade da Informação e do Conhecimento ao enfatizarem implicitamente a valorização das pessoas pela criatividade, pela promoção da interação entre usuários internos e externos por intermédio das redes de comunicação e pela valorização da informação e do conhecimento gerados em diferentes ambientes (TERRA, 2000).

\subsection{Análise dos conteúdos das ementas das disciplinas relacionadas à GI e a GC}

A obtenção das ementas foi por meio da Plataforma Sucupira que disponibiliza as disciplinas e suas ementas. A Tabela 4 apresenta as categorias dos conteúdos pertinentes da Gestão da Informação e do Conhecimento:

Tabela 4 - Temas dos conteúdos abordados sobre Gestão da Informação e do Conhecimento

\begin{tabular}{l|c|c}
\multicolumn{1}{c|}{ Categorias } & Frequência & $\%$ \\
\hline Gestão da Informação & 30 & $31,4 \%$ \\
\hline Gestão do Conhecimento & 23 & $24,1 \%$ \\
\hline Competência Informacional & 8 & $8,3 \%$ \\
\hline Inteligência Competitiva & 7 & $7,3 \%$ \\
\hline Inteligência Organizacional & 6 & $6,2 \%$ \\
\hline Cultura Informacional & 5 & $5,1 \%$ \\
\hline Gerenciamento Estratégico da Informação & 5 & $5,1 \%$ \\
\hline
\end{tabular}

Perspectivas em Gestão \& Conhecimento, João Pessoa, v. 10, número especial, p. 176-200, mar. 2020. 


\begin{tabular}{l|c|c}
\hline Cultura Organizacional & 4 & $4,1 \%$ \\
\hline Fluxo da Informação & 2 & $2,1 \%$ \\
\hline Comportamento Organizacional & 2 & $2,1 \%$ \\
\hline Aprendizagem Organizacional & 2 & $2,1 \%$ \\
\hline Conhecimento Organizacional & 2 & $2,1 \%$ \\
\hline Total de categorias (12) & $\mathbf{9 5}$ & $100 \%$ \\
\hline Fonte: Dados da pesquisa (2019)
\end{tabular}

A categoria que mais incide é a "Gestão da Informação" que corresponde a 31,4\% de frequência e a "Gestão do Conhecimento" a 24,1\%. Assim, infere-se que as ementas dos cursos de pós-graduação apresentam uma incidência relevante no que diz respeito aos conteúdos da GI e da GC.

A "Competência Informacional" corresponde a 7,3\% dos temas e está relacionada à necessidade de se exercer o domínio sobre o crescente universo informacional, incorporando habilidades, conhecimentos e valores relacionados à busca, acesso, avaliação, organização e difusão da informação e do conhecimento. A "Inteligência Competitiva corresponde a 8,3\%. Nesta categoria, os conteúdos abrangem as definições e conceitos sobre inovação, os tipos e necessidades de inovação para todas as organizações e as principais etapas da Gestão da Inovação, além dos processos informacionais adotados pelas organizações em conexão com a Administração Estratégica, Inteligência Competitiva e GC.

As categorias "Cultura Informacional" e "Gerenciamento Estratégico da Informação" representam 5,1\% dos temas e abordam os conteúdos, os modelos, as dimensões e as ferramentas da GC para o gerenciamento do conhecimento nas organizações. Segundo Valentim (2004) para gerenciar o conhecimento nas organizações é fundamental compreender que o conhecimento gerado por cada indivíduo organizacional necessita ser compartilhado aos demais membros. Para que isso ocorra é preciso de ações sistemáticas que garantam o compartilhamento do conhecimento entre os membros de uma organização. Assim, é necessário que a organização aja como gestora do conhecimento criado internamente, de modo a beneficiar sua própria capacidade de atuação.

As categorias "Fluxo da Informação", "Comportamento Organizacional", "Aprendizagem Organizacional" e "Conhecimento Organizacional" ocorreram em 2,1\%. A categoria "Fluxos de informação" trata de conteúdo sobre os fluxos e usos da informação. Em relação ao "Comportamento Organizacional" busca-se estudar o comportamento das pessoas nas organizações e o seu desempenho de forma geral. A categoria "Aprendizagem Organizacional" está inserida na abordagem sobre o conhecimento e aprendizagem organizacional. No que diz respeito ao "Conhecimento Organizacional" verifica-se a importância de gerenciar o intelecto humano visando criar novos conhecimentos e aprimorar os serviços e produtos das organizações.

A categoria "Inteligência Organizacional" com 6,2\% da ocorrência, busca desenvolver no aluno, a capacidade de identificar situações que justifiquem iniciativas de aperfeiçoar, conceber, projetar, implementar e operar os sistemas, utilizando recursos intelectuais, materiais e financeiros nas organizações.

A categoria "Cultura Organizacional" é apresentada com 4,1\%. Nesta categoria são incluídos conteúdos que versam sobre a cultura e o comportamento informacional no ambiente das organizações.

Apresentadas as categorias dos conteúdos de Gl e GC, os mais abordados referem-se a inteligência competitiva, competência informacional, inteligência organizacional, cultura informacional, gerenciamento estratégico da informação, cultura organizacional, fluxo da informação, comportamento organizacional, aprendizagem organizacional e conhecimento organizacional. Isto significa a emergência de temas (Figura 2) que devem estar inseridos nos

Perspectivas em Gestão \& Conhecimento, João Pessoa, v. 10, número especial, p. 176-200, mar. 2020. 
demais conteúdos das disciplinas dos programas de pós-graduação em $\mathrm{Cl}$ que ainda não contemplam em seus componentes curriculares.

Figura 2 - Representação das categorias dos conteúdos emergentes da GI e GC

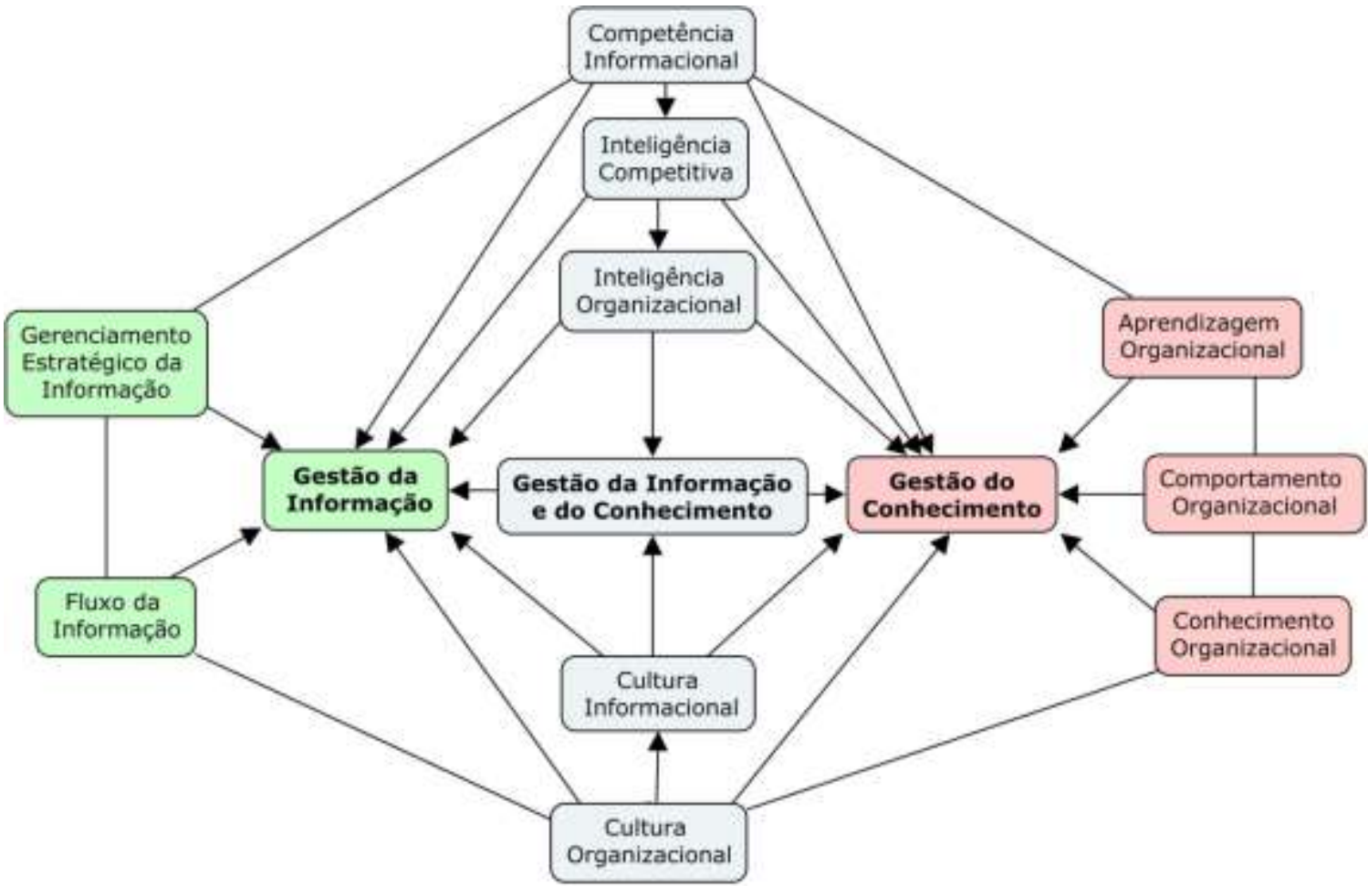

Fonte: Elaborado pelos autores por meio do Software Cmap Tools

Estas temáticas definem as abordagens das disciplinas de GI e GC, tornando-se os conteúdos emergentes para garantir o aprimoramento dos currículos às novas exigências da sociedade. Com o impacto das Tecnologias de Informação e Comunicação (TIC), surgiram novas demandas dirigidas ao próprio funcionamento da sociedade como a necessidade de se pôr em marcha e manter, como situação de equilíbrio dinâmico, amplo processo de revisão curricular em todos os níveis e áreas da educação. Segundo Takahashi (2000) um reposicionamento dos Parâmetros Curriculares Nacionais deve ser considerado no nível de pós-graduação inserindo $\mathrm{TIC}$, que é o caso dos programas de pós-graduação em $\mathrm{Cl}$. O autor afirma que muitos países se referem à necessidade de se acelerar a formação de especialistas, não somente para fazer face às necessidades do mercado em termos numéricos, mas principalmente para se adequar à velocidade de evolução da TIC.

Os conteúdos das ementas relacionados à Gl e a GC garantem a formação do profissional em nível de pós-graduação no sentido de prepará-lo para se adequar aos ambientes de negócio cada vez mais complexos, de maiores exigências de qualidade e especialização de conhecimentos.

\section{CONSIDERAÇÕES FINAIS}

Os resultados obtidos permitem inferir que a maioria dos programas denomina-se de Ciência da Informação, suas linhas de pesquisa incorporam a Gestão da Informação e a Gestão do Conhecimento em seus estudos que vêm sendo ofertados nos níveis de mestrados (acadêmico e profissional) e doutorado. Os eixos temáticos das disciplinas de GIC são

Perspectivas em Gestão \& Conhecimento, João Pessoa, v. 10, número especial, p. 176-200, mar. 2020. 
predominantes em cursos com alta avaliação pela CAPES e tem predominância dos conteúdos emergentes em GI e GC.

Ao analisar os conteúdos abordados nas disciplinas na área de Gl e GC nos cursos de pós-graduação em Ciência da Informação em nível nacional, constatou-se que os programas identificados se destacaram com disciplinas compatíveis com esta área.

Cabe ressaltar que as IES que possuem programas de pós-graduação em $\mathrm{Cl}$ e ainda não contemplam o eixo temático analisado, devem buscar inserir a GIC em seus currículos principalmente com os aspectos apresentados nos resultados, como: inteligência competitiva organizacional; competência informacional; cultura organizacional e informacional; gerenciamento estratégico da informação; fluxo da informação; comportamento organizacional; aprendizagem organizacional e conhecimento organizacional, considerando as tendências da Ciência da Informação rumo aos aspectos emanados pela Sociedade da informação e do Conhecimento, caracterizada como onda ou era econômica, em que a aprendizagem nas organizações é condição sine qua non.

A pesquisa apresenta perspectivas positivas em relação às abordagens que estão sendo inseridas nos cursos de pós-graduação em $\mathrm{Cl}$. Indica que as transformações estão acompanhando os reflexos da Sociedade em vigência, rumo às preocupações com o intenso fluxo da informação e a corrida desenfreada em busca de conhecimentos estratégicos para a sustentabilidade das organizações e o crescimento das pessoas. Esta realidade impacta as organizações que buscam a cada dia desempenhar seu papel de gestora de informações e de conhecimentos e conduzem a Ciência da Informação ao cumprimento dos paradigmas cognitivo e social que as compete reconhecer.

Contudo, as práticas da Gl e da GC nos ambientes organizacionais são condições para a sobrevivência das mesmas, por meio das pessoas que a conduzem. Isso implica que a $\mathrm{Cl}$ vem assumindo sua responsabilidade social ao despertar sobre a abrangência e complexidade do seu objeto de estudo. As implicações dessa realidade, certamente resultarão em pesquisas científicas inovadoras que definirão o papel da área em nossa Sociedade.

Ao fim deste relato, cabe ressaltar a necessidade em dar continuidade à pesquisa com o propósito de identificar as tendências inovadoras das abordagens da Gestão da informação e do Conhecimento nos programas selecionados, em relação aos avanços da produção científica na Ciência da Informação.

\section{REFERÊNCIAS}

ALVES, M. F.; OLIVEIRA, J. F. Pós-graduação no Brasil: do regime militar aos dias atuais. Revista Brasileira de Política e Administração da Educação, Goiânia, v. 30, n. 2, p. 351-376, 2014. Disponível em: https://seer.ufrgs.br/rbpae/article/view/53680. Acesso em: 13 nov. 2019.

AMORIM, F. B.; TOMAÉL, M. I. Gestão da informação e Gestão do conhecimento na prática organizacional: análise de estudos de casos. Revista Digital de Biblioteconomia e Ciência da Informação, Campinas, v. 8, n. 2, p. 01-22, 2011. Disponível em: https://periodicos.sbu.unicamp.br/ojs/index.php/rdbci/article/view/1931. Acesso em: 12 nov. 2019.

ANGELONI, M. T. Organizações do conhecimento: infra-estrutura, pessoas e tecnologia. 2. ed. São Paulo: Saraiva, 2008.

Perspectivas em Gestão \& Conhecimento, João Pessoa, v. 10, número especial, p. 176-200, mar. 2020. 
ARAÚJO, C. A. Á. Teorias e tendências contemporâneas da ciência da informação. Informação em Pauta, Fortaleza, v. 2, n. 2, p. 9-34, jul./dez. 2017. Disponível em: http://periodicos.ufc.br/informacaoempauta/article/view/20162/71589. Acesso em: 21 nov. 2019.

ARAÚJO, C. A. À. Fundamentos da ciência da informação: correntes teóricas e o conceito de informação. Perspectivas em Gestão \& Conhecimento, João Pessoa, v.4, n.1, p.57-79, jan./jun. 2014. Disponível em: http://periodicos.ufpb.br/ojs2/index.php/pgc/article/view/19120/10827. Acesso em: 20 nov. 2019.

BARBOSA, R. R. Gestão da informação e do conhecimento: origens, polêmicas e perspectivas. Informação \& Informação, Londrina, v.13, n. esp., p.1-25, 2008. Disponível em: http://www.uel.br/revistas/uel/index.php/informacao/article/view/1843/1556. Acesso em: 10 nov. 2019.

BARDIN, L. Análise de conteúdo. São Paulo: Edições 70, 2011.

BELL, D. O. 0 advento da Sociedade Pós-industrial. São Paulo: Cultrix, 1976.

BETTENCOURT, M. P.; CIANCONI, R. Gestão do Conhecimento: um olhar sob a perspectiva da Ciência da Informação. In: ENCONTRO NACIONAL DE PESQUISA EM CIÊNCIA DA INFORMAÇÃO, 13, 2012. Rio de Janeiro. Anais... Rio de Janeiro, ANCIB, 2012. Disponível em: http://www.brapci.inf.br/index.php/article/view/0000013195/d73406faab77e262347ca30040 e2c37d. Acesso em: 28 out. 2019.

BICALHO, L.; OLIVEIRA, M. A teoria e a prática da interdisciplinaridade em Ciência da Informação. Perspectivas em Ciência da Informação, Belo Horizonte, v.16, n.3, Jul./Set. 2011. Disponível em: http://portaldeperiodicos.eci.ufmg.br/index.php/pci/article/view/1245/892. Acesso em: 10 nov. 2019.

BRAMBILLA, S. D. S. Interfaces da Informação: Tendências temáticas da Pós-graduação. 2007. Dissertação (Mestrado em Comunicação e Informação) - Universidade Federal do Rio Grande do Sul, Porto Alegre, 2007. Disponível em: https://www.lume.ufrgs.br/handle/10183/10058. Acesso em: 16 nov. 2019.

CHOO, C. W. A organização do conhecimento: como as organizações usam a informação para criar significado, construir conhecimento e tomar decisões. 3. ed. São Paulo: Editora Senac, 2003.

DAVENPORT, T. H. Ecologia da informação: por que só a tecnologia não basta para o sucesso na era da informação. São Paulo: Futura, 1998.

MARCONI, M. A.; LAKATOS, E. M. Metodologia científica. 5. ed. São Paulo: Atlas, 2011.

MARCHIORI, P. Z. A ciência e a gestão da informação: compatibilidades no espaço profissional. Ciência da Informação, Brasília, v. 31, n. 2, p. 72-79, 2002. Disponível em: http://revista.ibict.br/ciinf/article/view/962/999. Acesso em: 16 nov. 2019.

Perspectivas em Gestão \& Conhecimento, João Pessoa, v. 10, número especial, p. 176-200, mar. 2020. 
MARTELETO, R. M. A pesquisa em Ciência da Informação no Brasil: marcos institucionais, cenários e perspectivas. Perspectivas em Ciência da Informação, v. 14, número especial, p. 1940, 2009.

MCGREE, J. V.; PRUSAK, L. Gerenciamento estratégico da informação: aumento a competitividade e a eficiência de sua empresa utilizando a informação como uma ferramenta estratégica. Rio de Janeiro: Campus, 1994.

MONTEIRO, S. A.; DUARTE, E. N. Bases teóricas da gestão da informação: da gênese às relações interdisciplinares. InCID: R. Ci. Inf. e Doc., Ribeirão Preto, v. 9, n. 2, p. 89-106, set. 2018/fev. 2019.

MOREIRA, F. M.; VALENTIM, M. L. P. ; SANT'ANA, R. C. G. A interdisciplinaridade da Ciência da Informação e suas contribuições no estudo do compartilhamento de dados governamentais na Internet. Em Questão, Porto Alegre, v. 24, p. 300-329, 2018.

NASSIF, M. E.; PAULA, C. P. A.; CRIVELLARI, H. M. T. Estudos sobre "Gestão da Informação e do Conhecimento" e "Trabalho" no PPGCI: origens, trajetória e perspectivas futuras. Perspectivas em Ciência da Informação, Belo Horizonte, v.24, número especial, p.102-129, jan./mar. 2019. Disponível em: http://portaldeperiodicos.eci.ufmg.br/index.php/pci/article/view/3896. Acesso em: 25 jan. 2020.

NONAKA, I; TAKEUCHI, H. Criação de conhecimento na empresa. Rio de Janeiro: Elsevier, 1997.

NONAKA, I.; TAKEUCHI, H. Gestão do Conhecimento. Porto Alegre: Bookman, 2008.

ODDONE, N. L. de Q. S. Ciência da Informação no Brasil. In: ENCONTRO NACIONAL DE PESQUISA EM CIÊNCIA DA INFORMAÇÃO (ENANCIB), 6., 2005. Anais [...]. Florianópolis: UFMG, 2005, p.135-160. Disponível em: http://www.arquivar.com.br/espaco profissional/sala leitura/teses-dissertacoes-emonografias/Lydia e a Ciencia da Informacao no Brasil.pdf. Acesso em. 14 nov. 2019.

PINHEIRO, L. V. R. Ciência da Informação: desdobramentos disciplinares, interdisciplinaridade e transdisciplinaridade. In: GONZÁLEZ DE GÓMEZ, M. N.; ORICO, E. G. D. (Org.). Políticas de memória e informação. Natal: EDUFRN, 2006. p.111-142. Disponível em: http://repositorio.ibict.br/bitstream/123456789/18/1/Pinheirodesdobramentos.pdf. Acesso em: 20 nov. 2019.

PINHEIRO, L.V.R.; LOUREIRO, J.M.M. Traçados e limites da ciência da informação. Ciência da Informação, Brasília, v. 24, n.1, p. 42-53, 1995. Disponível em: http://revista.ibict.br/ciinf/article/view/609. Acesso em: 14 nov. 2019.

PLATAFORMA SUCUPIRA. Cursos avaliados e reconhecidos. Brasília: 2019. Disponível em: https://sucupira.capes.gov.br/sucupira/public/index.xhtml. Acesso em: 16 nov. 2019.

PRODANOV, C. C.; FREITAS, E. C. Metodologia do trabalho científico: métodos e técnicas da pesquisa e do trabalho científico. 2.ed. Novo Hamburgo: Feevale, 2013.

Perspectivas em Gestão \& Conhecimento, João Pessoa, v. 10, número especial, p. 176-200, mar. 2020. 
PONJUÁN DANTE, G. Gestión de información: dimensiones e implementación para el éxito organizacional. Rosario: Nuevo Parhadigma, 2004. 2018p.

SANTOS, B. R. P. dos; DAMIAN, I. P. M. Análise Curricular da Gestão do Conhecimento em programas de Pós-graduação em Ciência da Informação no Brasil. In: ENCONTRO NACIONAL DE PESQUISA EM CIÊNCIA DA INFORMAÇÃO (ENANCIB). 29., 2018, Anais [...]. Londrina: UEL, 2018, p. 2848-2856. Disponível em: http://enancib.marilia.unesp.br/index.php/XIXENANCIB/xixenancib/schedConf/presentations. Acesso em: 16 nov. 2019.

SANTOS, R. R.; LLARENA, R. A. da S. LIRA, S. Conhecimento: conceitos, reflexões e aproximações. In: DUARTE, E. N.; LLARENA, R. A. da S. LIRA, S. (Org.). Da Informação à Auditoria de Conhecimento: a base para a inteligência organizacional. João Pessoa: Ed. UFPB, 2014. cap. 2, p. 45-78.

SOUZA, F. C. A formação acadêmica de bibliotecários e cientistas da informação e sua visibilidade, identidade e reconhecimento social no Brasil. Informação \& Sociedade: estudos, João Pessoa, v. 16, n. 1, p. 23-34, 2006 . Disponível em: http://www.brapci.inf.br/index.php/article/view/0000004164/433c71d141e0163bc42944b8ee fa0c43. Acesso em: 09 nov. 2019.

SOUZA, E. D.; DIAS, E. J. W.; NASSIF, M. E. A gestão da informação e do conhecimento na ciência da informação: perspectivas teóricas e práticas organizacionais. Informação \& Sociedade: estudos, João Pessoa, v. 21, n. 1, p. 55-70, 2011. Disponível em: http://www.periodicos.ufpb.br/ojs2/index.php/ies/article/view/4039. Acesso em: 13 nov. 2019.

SOUZA, I. G. C. de O.; DUARTE, E. N. Dimensões de um modelo de gestão da informação no campo da ciência da informação: uma revelação da produção científica do ENANCIB. Liinc em Revista. Rio de Janeiro, v. 7, n. 1, p. 152-169, 2011. Disponível em: http://revista.ibict.br/liinc/article/view/3276/2898. Acesso em: 9 nov. 2019.

SOUZA, R. F.; STUMPF, I. R. C. Ciência da Informação como área do conhecimento: abordagem no contexto da pesquisa e da Pós-Graduação no Brasil. Perspectiva em Ciência da Informação, Belo Horizonte, v. 14, número especial, p. 42-58, 2009. Disponível em: http://portaldeperiodicos.eci.ufmg.br/index.php/pci/article/view/901. Acesso em: 13 nov. 2019.

TAKAHASHI, T. (Org). Sociedade da informação no Brasil: livro verde. Brasília: Ministério da Ciência e Tecnologia, 2000. Disponível em: https://www.governodigital.gov.br/documentos-earquivos/livroverde.pdf. Acesso em: 26 nov. 2019.

TARAPANOFF, K. Informação, conhecimento e inteligência em corporações: relações e complementaridade. In: TARAPANOFF, K. (Org.). Inteligência, informação e conhecimento. Brasília: IBICT, UNESCO, 2006. p. 19-35.

TERRA, J. C. C. Gestão do conhecimento: o grande desafio empresarial: uma abordagem baseada no aprendizado e na criatividade. São Paulo: Negócio Ed., 2000. 283p.

Perspectivas em Gestão \& Conhecimento, João Pessoa, v. 10, número especial, p. 176-200, mar. 2020. 
TOFFLER, A. A terceira onda. 16 ed. Rio de Janeiro, Record, 1990.

VALENTIM, Marta Ligia Pomim (org.). Gestão, mediação e uso da informação. São Paulo: Cultura Acadêmica, 2010.

VALENTIM, M. Gestão da informação e Gestão do conhecimento: especificidades e convergências, 2004. Disponível em: www.ofaj.com.br. Acesso em: 27 out. 2019.

WILSON, T. D. Information management. In: FEATHER, J.; STURGES, P. (Ed.). International Encyclopedia of Information and Library Science. Londres: Rout leg, 2002.

Artigo recebido em 08/12/2019 e aceito para publicação em 10/03/2020

Perspectivas em Gestão \& Conhecimento, João Pessoa, v. 10, número especial, p. 176-200, mar. 2020. 